\title{
Synthesis, Characterization and Antibacterial Activity of Carbamate Derivatives of Isatin
}

\author{
SARRAH SATTAR JABBAR \\ Department of Pharmaceutical Chemistry, Collage of Pharmacy, University of Baghdad, Baghdad, Iraq. \\ ${ }^{*}$ Corresponding author E-mail: ph.sarahsattar@gmail .com \\ http://dx.doi.org/10.13005/ojc/3404041
}

(Received: May 29, 2018; Accepted: August 02, 2018)

\begin{abstract}
In search of novel antibacterial agent, a series of new isatin derivatives(3a-d)have been synthesized by condensation isatin(2,3-indolinendione) with piperidine(hexahydropyridine), hydrazine hydrate and Boc-amino acids respectively. Compounds synthesized have been characterized by IR spectroscopy and elemental analysis. In addition, the in vitro antibacterial properties have been tested against E. coli, P. aeruginosa, and Bacillus cereus, S. aureus by employing the well diffusion technique. A majority of the synthesized compounds were showing good antibacterial activity and from comparisons of the compounds, where $3 \mathrm{~d}$ has been determined to be the most active compound.
\end{abstract}

Keywords: Isatin, Isatin-3- hydrazine, N-Mannich base, Boc-amino acid,

Carbamate derivatives, Antibacterial activity.

\section{INTRODUCTION}

Isatin (2,3-indolinendione), is a heterocyclic compound of significant importance in medicinal chemistry. The keto group at position 2 and particularly at position 3 can enter into addition reactions at the $\mathrm{C}-\mathrm{O}$ bond and into condensation reactions, through the primary amine group, compounds of the isatin series are capable of entering into $\mathrm{N}$-alkylation and $\mathrm{N}$-acylation and into Mannich and Michael reactions ${ }^{1}$. The presence of several reaction centers in isatin and its derivatives render them capable of participating in a large number of reactions ${ }^{1}$. Indole derivatives have been found to possess several biological properties, including antimicrobial ${ }^{2}$, antibiotic ${ }^{3}$, anti-inflammatory, analgesic, anticonvulsant, antimalarial, anticancer, antiulcer, antileishmanial, contraceptive and antioxidant activities ${ }^{4}$. Isatin is able to participate in a broad range of synthetic reactions, leading to its extensive use as a precursor molecule in medicinal chemistry ${ }^{1}$. Preparation of different semisynthetic derivatives of isatin based on structure-activity relationship has been one of the best approaches. On the other hand carbamate-bearing molecules has been found to have great potential in the field of antimicrobial agents. So the incorporation of privileged chemical moieties, Boc-amino acids as

This is an Open Access article licensed under a Creative Commons Attribution-Non Commercial-Share Alike 4.0 International License (https://creativecommons.org/licenses/by-nc-sa/4.0/), which permits unrestricted Non Commercial use, distribution and reproduction in any medium, provided the original work is properly cited. 
Carbamate-bearing molecules linked to compound 2 through amide bond. carbamate-bearing molecules play an important role in modern drug discovery and medicinal chemistry. Organic carbamates (or urethanes) are structural elements of many approved therapeutic agents. Structurally, the carbamate functionality is related to amide-ester hybrid features and, in general, displays very good chemical and proteolytic stabilities. This is mainly due to their chemical stability and capability to permeate cell membranes. Another unique feature of carbamates is their ability to modulate interand intramolecular interactions with the target enzymes or receptors. Therefore a carbamate offers opportunities for modulation of biological properties and improvement in stability and pharmacokinetic properties $^{5}$.

\section{MATERIALS AND METHODS}

\section{Chemicals and Reagents}

All solvents used were of laboratory grade , Ethyl chloroformate (ECF) was obtained from Sigma Aldrich/Germany, Boc-L glycine; Boc-L-alanine, Boc-Lvaline and Boc-L-proline were obtained from Shanghai World Yang Chemical/China. Isatin and Piperidine were obtained from Sigma Aldrich/Germany.

\section{Apparatus}

Melting points (uncorrected) were determined using electrical melting point apparatus, Electro-thermal 9300, USA. The IR spectra were recorded in $\mathrm{KBr}$ disk on $\mathrm{FT}$-IR spectrophotometer /Shimadzu. Compounds were routinely checked for their purity on Silica gel G (Merck) Thin layer chromatography (TLC) plates. lodine chamber and UV lamp were used for visualization of TLC spots. Elemental data for $\mathrm{C}, \mathrm{H}$, and $\mathrm{N}$ were performed by Euro-vector EA 3000A, Italy. All the compound have presented satisfactory chemical analysis.

\section{Synthesis of 1-(piperidin-1-ylmethyl)indoline-2,3- dione (compound-1) ${ }^{6}$.}

The compound 1 has been synthesized as follows, as shown in scheme 1: Isatin(2,3indolineendione) (1 $\mathrm{gr}, 0.00679$ mole) was dissolved in $(10 \mathrm{~mL})$ methanol and then formaladehyde $37 \%, 2 \mathrm{~mL}$ was added to the mixture. The reaction mixture was cooled to $0^{\circ} \mathrm{C}$ and then piperidine (hexahydropyridine) (00679 mole, 0.57gr) was added with stirring. The stirring was continues for $1 \mathrm{~h}$ at room temperature . the precipitate collected and recrystallized from methanol and the required compound was obtained as orang solid $. \mathrm{M} . \mathrm{WT}=244$, $M . F=C_{14} H_{16} N_{2} O_{2}, m . p=142-144, R_{f}: 0.56$ (ethanol :chloroform, UV active). The elemental Analysis: found C, 68.91 Cal. C, 68.83 ; found $\mathrm{H}, 6.60$, Cal. $\mathrm{H}, 6.60$; found N, 11.48, Cal. N, 11.47 , IR $\left(\mathrm{cm}^{-1}\right)^{6}$ : 2941 (C-H str. $\mathrm{CH}_{2}$ Asy.) , $2852 \mathrm{C}-\mathrm{H}$ str. $\mathrm{CH}_{2}$ sy.), 1348 (C-N aliphatic), 1469-1412 (C=C Ar.), 3043 (C-H str. Ar.), 1732 (C=O indole), 1612(CO-NH) , 860-762 ( $\mathrm{HC}=$ Ar. bending).

Synthesis of (Z)-3-hydrazono-1-(piperidin-1ylmethyl)indolin-2-one(compound2) ${ }^{7}$.

The compound 2 has been synthesized as follows, as shown in scheme 1: compound-1 (0.005mole, $0.7 \mathrm{gr})$ was dissolved in methanol $(10 \mathrm{~mL})$ and added hydrazine hydrate $(80 \%)$ while shaking. the reaction mixture was refluxed for $30 \mathrm{~min}$. then the solution was allowed to cool to RT and left at refg. overnight and the product obtained was recrystallized from petroleum ether as yellow ppt., m.p=165-170, M.WT=258, M.F $=\mathrm{C}_{14} \mathrm{H}_{18} \mathrm{~N}_{4} \mathrm{O}$, $\mathrm{R}_{\mathrm{f}}: 0.54$ (ethanol :chloroform , UV active). The elemental Analysis: found C, 65.17, Cal. C,65.09 ; found $H, 7.03$, Cal. $H, 7.02$; found $N, 21.71$, Cal. N, 21.69, IR $\left(\mathrm{cm}^{-1}\right)^{7}: 1660(\mathrm{C}=\mathrm{N}) ; 1550-1464(\mathrm{C}=\mathrm{C}$ Aromatic); 3357, 3155 (N-H str. ), 3064 (C-H Ar.); 1685 ( $\mathrm{C}=\mathrm{O}$ amide isatin), 931-677( $\mathrm{HC}=\mathrm{Ar}$. bending), 2931-2850(C-H aliphatic).

\section{General procedure for synthesis of compounds (3a-d)}

Compound ( $3 a-d)$ have been synthesized by the mixed anhydride method ${ }^{8}$, as shown in (scheme 1). To a solution of Boc-amino acid $(2.28 \mathrm{mmol}, 0.4 \mathrm{gr})$ was dissolved in Tetrahydrofuran, THF $(5 \mathrm{~mL})$ containing TEA (2.28 mmol, $0.24 \mathrm{gr})$ at $-10^{\circ} \mathrm{C}$ were added Ethyl chloroformate, ECF $(2.28 \mathrm{mmol}, 0.24 \mathrm{gr})$ drop wise over a period of $10 \mathrm{~min}$. and the mixture was continuously stirred for further $30 \mathrm{~min}$. the solid was filtered off and filtrate was added to the solution of compound 2(2.28 mmol, 0.58gr) containing TEA (2.28 mmol, 0.24gr) in $5 \mathrm{~mL}$ DMF for $10 \mathrm{~min}$. and the mixture was stirred for $30 \mathrm{~min}$. at room temperature. The solvent DMF was evaporated and The precipitate was collected and was washed with ether. 


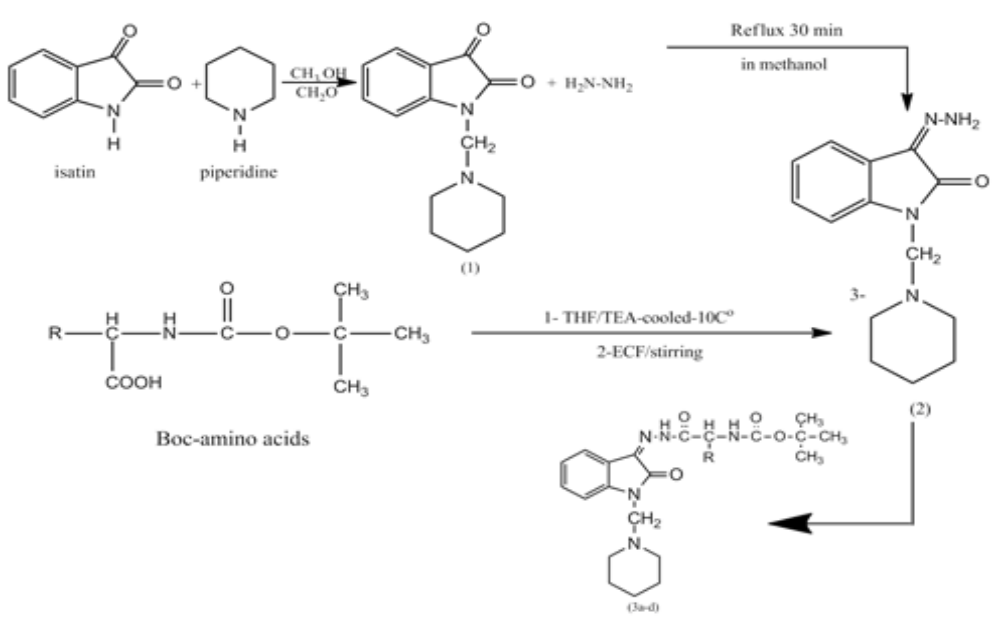

Scheme1. Synthesis of compound 3a-d

Synthesis of 3a, tert-butyl-(Z)-(2-oxo-2-(2-(2- TEA (2.28 mmol, $0.24 \mathrm{gr})$ was reacted with ECF (2.28 oxo-1-(piperidin-1-ylmethyl)indolin-3-ylidene) $\mathrm{mmol} 0.24 \mathrm{gr})$. compound $2(2.28 \mathrm{mmol}, 0.58 \mathrm{gr})$ in hydrazinyl)ethyl)carbamate

Compound 3a has been synthesized, as previously described and as shown in (scheme 1). Boc-glycine $(2.28 \mathrm{mmol}, 0.4 \mathrm{~g})$ in THF $(5 \mathrm{~mL})$ containing $\operatorname{DMF}(5 \mathrm{~mL})$ containing TEA $(2.28 \mathrm{mmol} 0.24 \mathrm{~g})$ was added. The reaction mixture was treated as described earlier. The physical appearance, percent yield and $R_{f}$ value are listed on Table (1).

Table 1: Physicochemical data of all synthesized test compounds (3a-d)

\begin{tabular}{|c|c|c|c|c|c|c|c|}
\hline Compound & structure & $\begin{array}{l}\text { Physical } \\
\text { appearance }\end{array}$ & $\begin{array}{c}\% \\
\text { Yield }\end{array}$ & m.p. $\left(\mathrm{C}^{\circ}\right)$ & $R_{f}$ valu & $\begin{array}{l}\text { e Molecular } \\
\text { formula }\end{array}$ & $\begin{array}{c}\text { Analysis (\%), } \\
\text { found (Calc.): } \\
\mathrm{C} ; \mathrm{H} ; \mathrm{N}\end{array}$ \\
\hline $3 a$ & & Pale yellow & 77 & $250-253$ & 0.5 & $\begin{array}{c}\mathrm{C}_{21} \mathrm{H}_{29} \mathrm{~N}_{5} \mathrm{O}_{4} \\
(415)\end{array}$ & $\begin{array}{l}60.70(60.71) \\
7.041(7.04) . \\
16.87(16.86)\end{array}$ \\
\hline $3 b$ & & Pale yellow & 62 & $266-269$ & 0.55 & $\begin{array}{c}\mathrm{C}_{22} \mathrm{H}_{31} \mathrm{~N}_{5} \mathrm{O}_{4} \\
(429)\end{array}$ & $\begin{array}{c}61.59(61.52) \\
7.291(7.28): \\
16.32(16.31)\end{array}$ \\
\hline $3 c$ & & pale yellow & 55 & 289-292 & 0.46 & $\begin{array}{c}\mathrm{C}_{24} \mathrm{H}_{35} \mathrm{~N}_{5} \mathrm{O}_{4} \\
(457)\end{array}$ & $\begin{array}{c}63.07(63.00 \\
7.719(7.71) \\
15.32(15.31)\end{array}$ \\
\hline $3 d$ & & Pale yellow & 35 & $295-298$ & 0.44 & $\begin{array}{c}\mathrm{C}_{24} \mathrm{H}_{33} \mathrm{~N}_{5} \mathrm{O}_{4} \\
(455)\end{array}$ & $\begin{array}{c}63.31(63.28) \\
7.31(7.30) \\
15.39(15.37)\end{array}$ \\
\hline
\end{tabular}


Synthesis of 3b, tert-butyl-(Z)-(1-oxo-1-(2-(2oxo-1-(piperidin-1-ylmethyl)indolin-3-ylidene) hydrazinyl)propan-2-yl)carbamate

Compound $3 \mathrm{~b}$ has been synthesized, as follows and as shown in (scheme1): Boc-alanine (2.1 $\mathrm{mmol}, 0.4 \mathrm{~g})$ in $5 \mathrm{~mL}$ of THF containing TEA $(2.1 \mathrm{mmol}, 0.22 \mathrm{~g})$ reacted with ECF $(2.1 \mathrm{mmol}$, $0.22 \mathrm{~g})$. compound $2(2.1 \mathrm{mmol}, 0.54 \mathrm{gr})$ in $\mathrm{DMF}(5 \mathrm{~mL})$ containing TEA $(2.1 \mathrm{mmol}, 0.22 \mathrm{~g})$ was added. The reaction mixture was treated as previously described. The physical appearance, percent yield and $R_{f}$ value are listed on Table (1).

Synthesis of 3c, tert-butyl-(Z)-(3-methyl-1-oxo1-(2-(2-oxo-1-(piperidin-1-ylmethyl)indolin-3ylidene)hydrazinyl)butan-2-yl)carbamate

Compound $3 \mathrm{c}$ has been synthesized, as follows and as shown in (scheme1): Boc-valine $(1.842 \mathrm{mmol}, 0.4 \mathrm{~g})$ in $5 \mathrm{~mL}$ of THF containing TEA $(1.842 \mathrm{mmol}, 0.186 \mathrm{~g})$ reacted with ECF $(1.842$ $\mathrm{mmol}, 0.2 \mathrm{~g})$. compound $2(1.842 \mathrm{mmol}, 0.48 \mathrm{gr})$ in $\mathrm{DMF}(5 \mathrm{~mL})$ containing TEA $(1.842 \mathrm{mmol}, 0.186 \mathrm{~g})$ was added. The mixture was treated as previously described. The physical appearance, percent yield and $\mathrm{Rf}$ value are listed on Table (1).

Synthesis of 3d, tert-butyl-(Z)-2-(2-(2-oxo1-(piperidin-1-ylmethyl)indolin-3-ylidene) hydrazine-1-carbonyl)pyrrolidine-1-carboxylate

Compound $3 d$ has been synthesized, as follows and as shown in (scheme1): Boc-proline $(1.86 \mathrm{mmol}, 0.4 \mathrm{~g})$ in THF $(5 \mathrm{~mL})$ containing TEA (1.86 $\mathrm{mmol}, 0.188 \mathrm{~g})$ was reacted with ECF $(1.86 \mathrm{mmol}$, $0.2 \mathrm{~g})$. compound $2(1.86 \mathrm{mmol}, 0.48 \mathrm{~g})$ in $\mathrm{DMF}(5 \mathrm{~mL})$ containing TEA (1.86 mmol, $0.188 \mathrm{~g})$ was added. The mixture was treated as previously described. The physical appearance, percent yield and $R_{f}$ value are listed in Table (1).

\section{RESULTS AND DISCUSSION}

Spectral data of synthesized compounds (3a-d)

The IR characteristic bands of compound $3 \mathrm{a}^{9-12}, 1745$ ( $\mathrm{C}=\mathrm{O}$ of urethane ), $1672 \quad\left(\mathrm{C}=\mathrm{O}\right.$ of $2^{0}$ Amide), 3336 ( $\mathrm{N}-\mathrm{H}$ of urethane), 1537 ( $\mathrm{N}-\mathrm{H}$ bending of urethane), $1622(\mathrm{C}=\mathrm{N}), 1165$ (C-O-C str. of urethane), 3036 (C-H str. Ar.) , 2939(C-H str. $\mathrm{CH}_{2}$
Asy), 2880 (C-H str. $\mathrm{CH}_{2}$ sy.) , 1454,1369 (C-H ben. $\mathrm{CH}_{3}$ of urethane Asy.,sy.)

The IR characteristic bands of compound $3 b^{9-12}, 1738$ ( $C=O$ of urethane ), $1691 \quad\left(\mathrm{C}=\mathrm{O}\right.$ of $2^{0}$ amide), 1165 (C-O-C str. of urethane), 3384 ( $\mathrm{N}-\mathrm{H}$ of urethane), 1518 ( $\mathrm{N}-\mathrm{H}$ bending of urethane), 1612 (C=N) , 3084 (C-H str. Ar.) , 2941 (C-H str. $\mathrm{CH}_{2}$ Asy), 2841 (C-H str. $\mathrm{CH}_{2}$ sy), 1456,1371 (C-H ben. $\mathrm{CH}_{3}$ of urethane Asy., sy.)

The IR characteristic bands of compound $3 c^{9-12}, 1707(\mathrm{C}=\mathrm{O}$ of urethane $), 1651 \quad\left(\mathrm{C}=\mathrm{O}\right.$ of $2^{0}$ Amide), 1161(C-O-C str. of urethane), $3340(\mathrm{~N}-\mathrm{H}$ of urethane), 1549 ( $\mathrm{N}-\mathrm{H}$ bending of urethane), 1549 (C=N), 3026 (C-H str. Ar.) , 2939(C-H str. $\mathrm{CH}_{2}$ Asy), 2885 (C-H str. $\mathrm{CH}_{2}$ sy) , 1462,1371 (C-H ben. $\mathrm{CH}_{3}$ of urethane Asy.,sy.) .

The IR characteristic bands of compound $3 d^{9-12}, 1741(\mathrm{C}=\mathrm{O}$ of urethane $), 1639\left(\mathrm{C}=\mathrm{O}\right.$ of $2^{0}$ Amide), 1130 (C-O-C str. of urethane), $3330(\mathrm{~N}-\mathrm{H}$ of urethane)), $1549(\mathrm{C}=\mathrm{N}), 3020(\mathrm{C}-\mathrm{H}$ str. Ar. $)$ ,2976 (C-H str. $\mathrm{CH}_{2}$ Asy), 2897 (C-H str. $\mathrm{CH}_{2}$ sy), 1431,1363 (C-H ben. $\mathrm{CH}_{3}$ of urethane Asy., sy.) .

\section{Antibacterial Evaluation}

The synthesized compounds were subjected to antibacterial evaluation by well-diffusion method $^{13}$. The zone of inhibition $(\mathrm{mm})$ was measured in comparison with cephalexin. These compounds were subjected against four types of bacteria (E. coli, P. aeruginosa, and Bacillus cereus, S. aureus). The antibacterial activity was performed in nutrient agar medium containing $E$. coli, $P$. aeruginosa and Bacillus cereus, $S$. aureus and the compounds used at concentrations $(250 \mu \mathrm{g} /$ well). The activity was determined after incubation for $24 \mathrm{~h}$ at $37^{\circ} \mathrm{C}$ by the comparison of inhibition of growth of bacteria by (cephalexin) using dimethylsulfoxide (DMSO) as the solvent.

The antibacterial evaluation revealed that the newly synthesized compounds, 3a-d showed reasonable antibacterial activities against $G(-)$ bacteria, such as $P$. aeruginosa and $G(+)$ bacteria, such as Bacillus cereus in comparison with cephalexin, which has no activity against these type of microbes. 
Table 2: Antibacterial activity of the new derivatives of isatin(diameter of the zone of inhibition $(\mathrm{mm})$ ) at $250 \mu \mathrm{g} / \mathrm{mL}$

Compound Escherichia coli. Pseudomonas aeruginosa Staphylococcus aureus Bacillus cereus.

\begin{tabular}{lcccc}
\hline DMSO & - & - & - & - \\
Cephalexin & 11 & - & 12 & - \\
$3 a$ & 9 & 12 & 8 & - \\
$3 b$ & 10 & 14 & 9 & 10 \\
$3 c$ & 10 & 15 & 10 & 11 \\
$3 d$ & 12 & 16 & 7 & 17 \\
\hline
\end{tabular}

Key to symbols: $(-)=$ no inhibition.

Compound 3a showed significant activity against $P$. aeruginosa and reduction in antibacterial activities against $S$. aureus and E. coli as compared with cephalexin. Compound $3 \mathrm{~b}$ showed significant activity against $P$. aeruginosa and Bacillus cereus, as compared with cephalexin.

However, Compound 3c showed significant activity against $P$. aeruginosa and moderate antibacterial activities against E. coli, S. aureus and Bacillus cereus as compared with cephalexin.

Compound 3d showed very significant activity against E. coli, P. aeruginosa and Bacillus cereus and slight activity towards $S$. aureus. This result indicates that compound $3 d$ has a broader spectrum of antibacterial activities, i.e. against both $\mathrm{G}(+)$ and $\mathrm{G}(-)$ bacteria.

\section{CONCLUSION}

A series of new derivatives of isatin have been synthesized successfully in appreciable yields and screened for their antibacterial activity using well diffusion method against bacterial strains ( $E$. coli, $P$. aeruginosa and Bacillus cereus, $S$. aureus). It is concluded that the new carbamate derivatives of isatin possess good antibacterial activities. Furthermore, the new derivative (compound $3 d$ ) has significant activity against $p$. auroginosa and Bacillus cereus.

\section{REFERENCE}

1. Pakravan, P.;Kashanian, S.; khodaei, M.M.; Harding, F.J., Pharmacol Rep., 2013, 65(2), 313-35.

2. Singh, U. K. ; Pandeya, S. N.;Singh , A. ; Srivastava, B. K.; Pandey, M. , IJPSDR., 2010, 2(2), 151-154.

3. Chhajed, S.S. ;Padwal, M. S., Int.J. ChemTech Res., 2010, 2(1), 209-213.

4. Srivastava, A. ; Pandey, S.N. , Int J Curr Pharm Rev Res., 2011, 1, 1-17.

5. Ghosh ,A. K. ; Brindisi, M., J Med Chem., 2015, 58(7), 2895-2940.

6. Al-kadhimi ,A.A.H.;Al-azzawi ,N.K.E.; Khalaf, A. I., J. Chem. Bio. Phy. Sci., 2015, 5(3), 2338-2349.

7. Coffey, K. E. ; Moreira, R. ; Abbas, F. Z. ; Murphy, G. K., Org.Biomol.Chem., 2015, 13, 682-685.
8. Ho Sik Rho; Heung Soo Baek; Duck Hee Kim; Ih Seop Chang , Bull. Korean Chem. Soc. 2006, 27(4), 584-586.

9. Asefnejad, A.;Khorasani, M.T.;Behnamghader, A.; Farsadzadeh, B.; Bonakdar, S., Int.J Nanomedicine., 2011, 6, 2375-2384.

10. Bandekar, J.; Klima, S., J. Mol. Struct., 1991, 263, 45-57.

11. Kambel, R. D.; Aliyu, B.A.; Barminas, J. T.; Akinterinwa, A., International Journal of Materials and Chemistry., 2017, 7(1), 1419.

12. Byczycski, Ł. ; Dutkiewicz, M. ; Maciejewsk, H., Polym. Bull., 2016, 73, 1247-1265.

13. Sridhar, S. K.; Saravanan, M.; Ramesh, A., Eur. J. Med. Chem., 2001, 36, 615-625. 